\title{
Education and Local Government Working Together: a Community Governance Approach
}

\author{
Bernardine Vester
}

\section{Introduction}

Relationships between the education and local government sectors have historically been related to matters such as rates impacts, building consents, attending to transport or community safety, or the use of parks, libraries and leisure facilities. Yet community well-being, for which local government is responsible, is influenced by the network of schools and other educational institutions within a particular geographic area, and the issues that affect them all. Education as an agent of well-being features strongly in the long term council community plans (LTCCPs) of local government (Reid, Scott \& McNeill, 2006).

It is far from clear how the two sectors might usefully work together. One possibility is to link the community outcomes process required under the Local Government Act 2002 to strategic planning and implementation processes within the education sector, thereby giving both central government and communities the potential to obtain better value from the resources they control to address challenging social, economic, cultural and environmental issues.

This article reports on research which suggests a model for engagement between these two sectors (see Vester, 2006). The model consists of levers which constitute a kind of 'community governance' for promoting community well-being through education.

Governance is the set of rules that frame decision making. Two aspects of governance - structures and processes - are relevant to the way in which relationships between local government and education can be developed, and provide a theoretical underpinning to the development of a model of engagement. Education decision making prior to 1989 involved hierarchical structures and processes driven by prescriptive rules and regulations. The 1989 education reforms removed the hierarchical structure within compulsory education and replaced it with a market structure. This structure offered greater parental empowerment and the removal of the state from micro-level decision making. However, markets have an atomistic tendency (Pierre \& Peters, 2000 , p.19). The many separate governing bodies of schools that collectively and theoretically form the 'market' for education have no economic incentive to cooperatively resolve problems shared with other actors. Indeed, it is possible to argue that the incentive exists for schools in a position of privilege to pass problems on to others, or to seek to insulate themselves against external influences. In a market environment, cohesive, strategic decision making across schools or post-compulsory education and training providers must be achieved through indirect steering mechanisms (such as central government purchasing decisions). This structural characteristic presents a key barrier to the relationship between local government and schools because it fragments institutions into isolated units of decision making with no requirement to engage with the strategic ambitions of territorial local authorities.

A further difficulty in the interface between education and local government in New Zealand arises out of the existence of a variable definition of 'community'. A school community is defined as 'parents', whereas the geographic community of territorial local authorities comprises 'all citizens'. School communities and local communities may have commonalities, but they are not the same. Education is no longer the exclusive preserve of central government, even though the state exercises powerful leverage over schools and other learning institutions through the prescription of curriculum, provision of funding, and education and administrative 'guidelines'. Instead, its governance structure is the private preserve of parents moderated by the input of employees. 
A key element of well-governed communities is community ownership of the fruits of their successes - and failures - in solving collective problems (Pierre $\&$ Peters, 2000, p.21). Communities can only achieve this when they 'own' the assets with which they work. A network of schools within a geographic area is a powerful community resource to meet the four well-beings of local government. The key challenge in creating community governance for education is to define the ways in which key actors may interact to create a sense of shared ownership in order to achieve a desired community outcome. This requires understanding the different structural frameworks that apply for each sector, and applying processes within those frameworks which enable action.

\section{Structural frameworks in the education sector}

The devolved 'market model' of education provision results in a very complicated network of actors operating in the sector. The key government institution is the Ministry of Education, although the Education Review Office (ERO), the New Zealand Qualifications Authority (NZQA) and the Tertiary Education Commission (TEC) also have very important and distinctive functions. These agencies set sector strategies.

However, there is no physical presence of these agencies in most local government geographic areas. Instead, the education sector presence in each of the 12 regional councils and 73 territorial local authorities consists of the education providers - that is, early childhood centres, schools and tertiary institutions. Each school contracts with the government through a 'charter' with the Crown for delivery of services. Schools, individually governed by boards of trustees made up of parents and led by a school principal, are expected to develop institutional strategic plans that are consistent with national education guidelines and national administration guidelines (known as NEGs and NAGs) - a form of 'purchase criteria' for government from the schools sector. The self-managing autonomy of schools results in very different strategic planning directions. While the recent creation of a national schooling strategy may help to align these strategic plans, there is no requirement to support a community-led approach.

Like schools, tertiary institutions are bound by the requirements of the Education Act and its amendments.
While each institution has its own constitutional governing body, there is a defined tertiary education strategy (known as the TES), and a regularly reviewed statement of tertiary education priorities (STEP), the purpose of which is to 'steer' the sector. This terminology is highly relevant to the concept of engagement of community in education. Recently announced changes underpinning government purchasing decisions for skills training imply the importance of connecting community strategic priorities to central government decision making. These tertiary sector changes are designed to encourage more collaborative planning processes, perhaps inclusive of local government interests. The responsibility for a 'regional facilitation process' rests with institutes of technology or polytechnics.

\section{Structural frameworks in the local gov- ernment sector}

The Local Government Act 2002 proposed the empowerment of local bodies to meet the needs of their communities and the development of a partnership between central and local government (Department of Internal Affairs, 2000, p.2). The drivers for change included growing international emphasis on the importance of networks in the development of community well-being (Putnam, 1993; Cox, 1995; Fukuyama, 1995) and the recognition that crosscutting policy issues, the so-called 'wicked issues' such as youth unemployment, crime and violence, urban poverty, health and intergenerational illiteracy (Clarke $\&$ Stewart, 1998), could only be dealt with through more holistic and more localised approaches.

The economic, social, cultural and environmental wellbeing that forms the core purpose of local government is to be delivered through consultation and decisionmaking processes that are tightly prescribed. The tool for defining community outcomes is the Long Term Council Community Plan (LTCCP), which describes a set of 'desired outcomes'.

The engagement and involvement of educators and education sector leaders in the development of the LTCCP is critical if the community's aspirations for educational outcomes are to be met. However, there is no specific requirement for schools - or indeed the education sector government agencies - to participate in this process. The challenge, therefore, is how to engage the education sector in community outcomes processes. 


\section{Processes for engagement: case studies}

Four case studies - Manukau City, the West Coast and two from Southland - illustrate processes for engagement that have developed out of these structural frameworks in each sector. Each case study described four elements: the drivers for engagement, the key actors and their actions which drove working relationships, the outcomes of the engagement and the shape of future action.

A key theme emerged from the case studies. In all regions, the regional economic development strategy was important to support a working partnership. While a key driver behind all case studies may have been a central government strategy (for increasing participation in tertiary education), central government policy (school network review policy) or central government institution (ERO), the local government economic development strategic context was critical to subsequent action. Each of these case study areas faces particular economic development challenges.

In Manukau the challenge has been significant population growth, social and cultural diversity and the requirement for enhanced population skill levels to meet labour market demand. The response was the establishment in 1999 of the City of Manukau Education Trust, which in 2002 became a council-controlled organisation. It now has specific responsibilities for addressing the desired outcomes for 'An Educated and Knowledgeable People', contained in the vision document developed by the Manukau City Council, Tomorrow's Manukau: Manukau Apopo.

In Southland, population decline and an export economy reliant on global markets have required improved population skill levels to meet future needs. The development of the zero fees policy at the Southern Institute of Technology in 2001 has demonstrably halted population decline and enhanced local skill development potential. This case study refers to the collaboration with local bodies and the Southland Community Trust and the Invercargill Licensing Trust to address the economic imperative.

The engagement of the Invercargill City Council and the mediating role of Venture Southland (the economic development agency for three territorial local authorities) in a highly controversial schooling reorganisation in 2003 supported the creation of solutions to a difficult local school network problem.
On the West Coast, the dependence on sunset/extractive industries, the emergence of tourism as an economic driver and the removal of isolation as an economic factor through the use of technology has driven an aspiration to improve workforce skill levels. The case study describes the responses of the West Coast Development Trust, councils and local schools and educational organisations to concerns raised by an ERO report about West Coast school performance. The West Coast Development Trust funded the implementation of a major literacy initiative in 2005 to understand and address the contribution the school's sector could make to meeting community skill needs.

Key actors came from across the community, local government, education and central government spectrum. Their leadership in working towards mutually desired outcomes points to the importance of strengthening relationships and making connections. They understood the usefulness of evidence and data to support outcomes. And they tapped into a wide range of community resources and expertise to solve problems. Analysis of the outcomes from collaborative action pointed to an emerging governance process which addresses issues affecting the broad network of schools and education institutions, and wider community well-being.

\section{Towards a community governance framework for education outcomes}

Peter McKinlay, addressing the role of community trusts, comments on the nature of the 'shared responsibility' inherent in the community governance approach:

Community governance is not about instruments of government, such as a local authority, imposing its own views on the community. Instead, it is about developing the means whereby the community itself develops its understanding of its preferred future(s) and the means of realising those. It is a process which needs to recognise the diversity within individual communities as well as the need for a robust process which can do the difficult things such as identify trade offs between different groups or different options and bring together the plans and policies of the various key actors through whom the community will want to work in order to achieve those futures. (McKinlay, 1999) 
A 'community governance framework' for education will reflect structures and processes that deliver whole-ofcommunity aspirations. By strengthening community understanding of the complex issues facing the sector, a wider range of resources can be brought to bear on solving 'wicked' social, cultural and economic problems. Working together around a shared vision of the future, the combined weight of community decision makers will result in community outcomes that meet the four well-beings of local government, as well as the strategic intentions in the education sector.

The settings under which community governance for education could operate are still untested. There can be no blueprint for ideal community governance (Bowles \& Gintis, 2001). However, the elements of well-governed communities were manifested in a variety of ways in the case studies. The case studies suggest a set of six governance levers that frame collaborative decision making and action in the community.

\section{A unifying vision, strategy or community plan}

A community governance approach demands consensus about desired outcomes. The narrower definitions of community contained in the Education Act (i.e. parents or other schools) make consultations on matters that have a long-term or wider community impact (such as developing new schools, restructuring school networks, or addressing matters of schooling achievement) less effective in addressing community aspirations. More robust community consultation processes are contained in the Local Government Act 2002. The research reviewed examples of economic development strategies or local government vision documents that have already made the connection between education outcomes and community desired outcomes. The mechanism with the greatest potential for making the engagement between education and local government deliver something of value to the community is the long term council community plan. For this reason, special attention should be paid to engaging the education sector in LTCCP processes; or for incorporating education plans into the LTCCP. This has to offer something of value to education sector leaders - most often, this will be resources and support. Equally, an education plan, shared by local government and the education sector, could be of considerable value to a community. The challenge in developing an education plan will be in finding mechanisms whereby school strategic planning and city or regional strategic planning can come together. The resource and facilitation for this will be particular to each area, but the opportunity to tap into 'community resources' for this purpose is worth exploring.

\section{Distributed leadership}

Governance and management tasks are shared in communities. People who have governance and management roles in a community may include:

- a mayor, councillors, community board members;

- runanga or iwi authorities;

- school trustees and their boards;

- trustees of community trusts;

- CEOs of community agencies, including economic development or community development agencies;

- business or workplace leaders, who can influence the shape of the local economy;

- school professional leaders;

- government agency leaders;

- political representatives.

The case studies point to the value of distributed leadership in a community, and the value of connecting leaders from different spheres to address community problems. The added value in applying governance and management leadership across the community to some larger problems having an impact on education is worth further research.

\section{Information and data to underpin decision making}

Over the last 10 years the education sector has been engaged in schooling improvement initiatives and projects which focus on using evidence and data about student progress to plan lessons and evaluate learning. New Zealand does not, however, have a national testing system, except in the senior secondary school. This allows for more flexibility to design programmes of learning that will meet the needs of diverse groups of students. However, the availability of reliable, benchmarked data to report student progress to parents, 
and schooling outcomes to communities, has been limited. This is not an argument for national testing. Rather, it is an argument for making data or information - some of which may already exist - available in a form which supports community understanding and awareness of issues which affect schooling outcomes in the local area. Public engagement in education, in the absence of reliable or meaningful information on student achievement at almost all levels except senior secondary, falls back on two opposite responses. The first is a supportive response, calling for donations or exhortations to work with children. There is no strategic linkage in a donations process, and consequently very little evidence of change as a result of community philanthropy. The second response is more critical. It calls for public accountability for schools, including greater obligations to report or explain or justify or be otherwise answerable through testing or exams.

The problem of poor information is that it results in general assumptions of school or government failure in managing schools or the schooling system. Although individual schools can claim high levels of community confidence, the schooling system is wide open to generalised accusations of failure. High-quality information, which can support measuring and auditing of outcomes from the sector, is a prerequisite for creating confidence in the network of schools serving a community. Information has been a driving force for the work of the ERO since its beginning. The key audience for this information has been parents. However, the importance of information for community decision makers has been under-emphasised. Measuring and auditing outcomes are an important part of the LTCCP community outcomes process. The process is still too new to identify whether community outcomes related to education can be properly measured using existing publicly-available data. This is an area meriting further research.

\section{Community resources - financial assets and expertise}

The case studies on the West Coast and in Southland demonstrated the powerful effect that community capital can have on community economic aspirations, when harnessed to education. Assets to be found in many communities include energy trusts, local government shareholdings in infrastructural companies such as ports and airports, licensing trusts, land, and community trusts distributing assets from community savings banks. These can become not simply a source of income for distribution, but a resource powerful enough to influence the economic development settings of the community.

All government agencies, local authorities and councilcontrolled organisations are required to spell out in statements of intent their objectives for the future. Their annual reports are carefully scrutinised. Through a process of negotiation with their communities, organisations that are stewards of community assets must set out their policies for investment and spending and explain how performance in pursuing objectives will be measured.

However, connecting these statements of intent, disbursement policies or resource management policies to community outcomes in education is a challenge. There is no obligation on trustees of community assets to connect those assets and resources to community strategies, unless there is a clear community demand for them to do so. A policy gap exists in this area.

\section{Collaborative activities, and inclusiveness in meeting shared goals}

The quality of community networks is important. Community leaders and education leaders need opportunities to spend time together, to actively seek opportunities to work together, and to consciously be inclusive of other stakeholders. The organising framework for education conspicuously lacks a connection to community decision makers. This provides a particular challenge for local government managers. The engagement of educators in defining community outcomes in relation to education is no less than that required to meet the consultation principles under section 82 of the Local Government Act 2002. However, there has to be openness from the education sector, too, in engaging in collaborations that are purposeful.

It is clearly easier to manage networks in smaller communities. The Southland and West Coast leadership networks are intensely interconnected, not as a result of geographical closeness but because of joint ventures and activities that form background relationships which can be subsequently applied to new collaborations. Even so, the research points to unrealised potential in educational development projects because there is no 
particular drive from within the education sector to be inclusive of players other than parents or other education sector professionals.

\section{Public debate and openness to community input}

In the public and community sectors, the use of statements of intent, annual reports and annual general meetings to provide a framework for public input is common practice. These offer opportunities for debate and build community awareness of governance decisions. The media plays an important role in democratic operation, and offers a means of sharing goals and including others.

Schools and public tertiary institutions, as public entities, must meet the same requirements as other Crown agencies. However, there is no obligation on schools to connect their annual plans and annual reports to community strategies. There are missed opportunities here. Firstly, if schools were to connect their strategies to community aspirations, they would have a greater opportunity of tapping into the resources targeted to those outcomes. Secondly, annual reports are an excellent mechanism for publicly self-reporting on outcomes, and for displaying achievements. But they are rarely available in the usual public access spaces - public libraries or the internet, for example - or accompanied by media releases. Thirdly, by publicly and collaboratively linking to an area network education plan, a school network might be in a better position to argue for a share of community asset distributions such as community and licensing trusts provide, which would make a real difference to learning outcomes.

\section{Capacity and capability to engage}

The gap in the capacity of the Ministry of Education to support engagement with local government is particularly striking. None of the officials from the ministry interviewed for the study appeared to understand local government processes for developing a community vision. Local government was seen as a regulator for property matters or traffic or safety issues. There is no ministry process for working with communities at the macro level. This is a gap that needs to be addressed if the Ministry of Education is to meet its strategic goal of supporting 'family and community engagement', or to deliver on the state sector promise to support a whole-of-government approach.

Finally, the capacity and capability of schools to engage with local government is limited by the understandings in the sector about the importance of such engagement, and the human resources (that is, people and time) available to effectively support connections. The literature and the practice seem to suggest that effective engagement will result from concrete projects that deliver value to participants.

\section{Conclusion}

The research set out to identify the nature of the relationship between local government and education. The central research question was: how can community 'well-being', as described by the Local Government Act 2002, be delivered through education? A community governance framework as a means of facilitating collaboration between local government and education has the potential both to assist in addressing schooling network issues, and more generally in helping to address some of the intractable 'wicked issues' of public policy. The framework responds to theories of social capital development. The community governance framework for education identifies a number of ways in which the relationship between the education sector, local government, and community can be advanced:

- Firstly, through an overarching vision-a community LTCCP, an economic development strategy, an education plan - which has been collaboratively developed and therefore is recognised and owned by all players.

- Secondly, through nurturing distributed leadership which engages with education issues on shared terms. This could be achieved through the creation of opportunities for education sector, community and other leaders to come together; or by deliberately encouraging the development of leadership capacity and capability across the community in cross-sector settings.

- Thirdly, by deliberately setting about gathering data and information about education, and publicly presenting it in accessible forms. The process itself will require deep engagement. However, local government is well placed to facilitate informationgathering and dissemination - through local libraries, media, community institutions, and so on. 
- Fourthly, by considering the range of community assets and resources that can be aligned to strategic actions, and ensuring that they add value to visions for economic development.

- Fifthly, through engaging in collaborative activities that arise out of consultation and dialogue, since action helps to form relationships (Timperley \& Robinson, 2002).

- Sixthly, through building the capacity and capability for local government and the education sector to engage with each other.

- And finally, by ensuring that there is an openness in processes - even when consultation is not mandated - so that there is an opportunity for leaders from the education sector and the community sector to plan and work together.

The community governance framework for education proposed here fits with the development goals for the state sector. Schools and education sector institutions are part of the state sector, even though they may not always recognise this. Their relationship to their community can build the trust and confidence they need to deliver outcomes, and maintain support into the future.

Local government has a powerful opportunity to work with education sector and community leaders to deliver educational outcomes that enhance community well-being. The potential exists for innovative and creative responses to community challenges when the education sector and local government work together with community well-being in mind. The structures and processes for realising that potential already exist. It requires only a new way of thinking about how to use them.

\section{References}

Bowles, S. \& H. Gintis (2001) Social Capital and Community Governance, working paper 01-01-003, Massachusetts: University of Massachusetts and Santa Fe Institute, retrieved from http://www.santaafe.edu/ research/publications/working-papers.php

Clarke, M \& J. Stewart (1998) Community Governance, Community Leadership and the New Local Government, York: Joseph Rowntree Foundation

Cox, A.D. (1995) A Truly Civil Society, Sydney: ABC Books
Department of Internal Affairs (2000) 'Statement of policy direction for review of Local Government Act 1974', Wellington: Department of Internal Affairs, 9 November

Fukuyama, F. (1995) Trust: the social virtues and the creation of prosperity, London: Hamish Hamilton

McKinlay, P. (1999) 'Putting the community into the Community Trust of Southland', address to the 1999 annual general meeting of the Community Trust of Southland, McKinlay Douglas Limited: Reading Room

Manukau City Council (2004) Tomorrow's Manukau: Manukau Apopo

Pierre, J. \& B.G. Peters (2000) Governance, Politics and the State, New York: St Martin's Press

Putnam, R. (1993) Bowling Alone: the collapse and revival of American community, New York: Simon and Schuster

Reid, M., C. Scott \& J. McNeill (2006) 'Strategic planning under the Local Government Act 2002: towards collaboration or compliance?', Policy Quarterly, 2 (2), pp.18-25

Timperley, H. \& V. Robinson (2002) Partnership: focusing the relationship on the task of school improvement, Wellington: New Zealand Council for Educational Research

Vester, B. (2006) 'Linking Education to Community Through Local Government', MPP thesis, Victoria University of Wellington

Bernardine Vester is a former secondary teacher and assistant principal. She served as vice-president of the Post Primary Teachers' Association from 1996 to 1998. Since 2000 she has been the chief executive of the City of Manukau Education Trust. During her 2002 Eisenhower Fellowship to the United States, Bernardine explored the role of community agencies in education. Bernardine was awarded the 2007 Holmes Prize in Public Policy for the research on which this article is based. 